\title{
- Invited Review - Understanding intestinal health in nursery pigs and the relevant nutritional strategies
}

\author{
Sung Woo Kim ${ }^{1, \star}$ and Marcos E. Duarte ${ }^{1}$
}

\author{
* Corresponding Author: Sung Woo Kim \\ Tel: +1-919-513-1494, Fax: +1-919-515-6884, \\ E-mail: sungwoo_kim@ncsu.edu \\ ${ }^{1}$ Department of Animal Science, North \\ Carolina State University, Raleigh, NC 27695, \\ USA \\ ORCID \\ Sung Woo Kim \\ https://orcid.org/0000-0003-4591-1943 \\ Marcos E. Duarte \\ https://orcid.org/0000-0003-0094-336X \\ Submitted Jan 11, 2021; Revised Jan 20, 2021; \\ Accepted Jan 23, 2021 \\ Parts of this review were presented at Animal \\ Bioscience Forum 2020 on Animal Bioscience \\ to Improve Animal Health and Production: \\ Immune, Herbs and Systems for Monogastric \\ Animals (December 9-10, 2020), which was \\ supported by Pathway Intermediates (http:// \\ www.pathway-intermediates.com)
}

\begin{abstract}
In the modern pig production, pigs are weaned at early age with immature intestine. Dietary and environmental factors challenge the intestine, specifically the jejunum, causing inflammation and oxidative stress followed by destruction of epithelial barrier and villus structures in the jejunum. Crypt cell proliferation increases to repair damages in the jejunum. Challenges to maintain the intestinal health have been shown to be related to changes in the profile of mucosa-associated microbiota in the jejunum of nursery pigs. All these processes can be quantified as biomarkers to determine status of intestinal health related to growth potential of nursery pigs. Nursery pigs with impaired intestinal health show reduced ability of nutrient digestion and thus reduced growth. A tremendous amount of research effort has been made to determine nutritional strategies to maintain or improve intestinal health and microbiota in nursery pigs. A large number of feed additives have been evaluated for their effectiveness on improving intestinal health and balancing intestinal microbiota in nursery pigs. Selected prebiotics, probiotics, postbiotics, and other bioactive compounds can be used in feeds to handle issues with intestinal health. Selection of these feed additives should aim modulating biomarkers indicating intestinal health. This review aims to define intestinal health and introduce examples of nutritional approaches to handle intestinal health in nursery pigs.
\end{abstract}

Keywords: Inflammation; Intestinal Health; Microbiota; Nutritional Strategies; Nursery Pigs; Oxidative Stress

\section{INTRODUCTION}

Since the first use of antibiotics for poultry in 1940's [1-3] and for swine in 1950's [4-6], they have been widely used for prophylaxis to handle issues with diseases as well as for growth promoting as antimicrobial growth promoters (AGP) in animal production [7-9]. However, due to emerging concerns over resistance to antibiotics for human, the use of AGP in animal feeds has been restricted or banned in several countries including Sweden (1986), Denmark (1995), EU (2006), Korea (2011), USA (2017), China (2020), and Vietnam (2020) [10-12].

Increased occurrence of gut diseases with the removal of AGP in feeds, however, enlightens pig producers and animal scientists the importance of concepts of intestinal health $[13,14]$, intestinal microbiota, and alternative feed additives. Importance of these topics is well shown by increased research activities. Simply searching the PubMed with keywords including intestinal health and microbiota in pigs provided over 1,900 peer-reviewed papers since 1960 . However, $90 \%$ of all papers are published since 2010 indicating increased challenges with intestinal health and interests in intestinal microbiota of pigs especially 


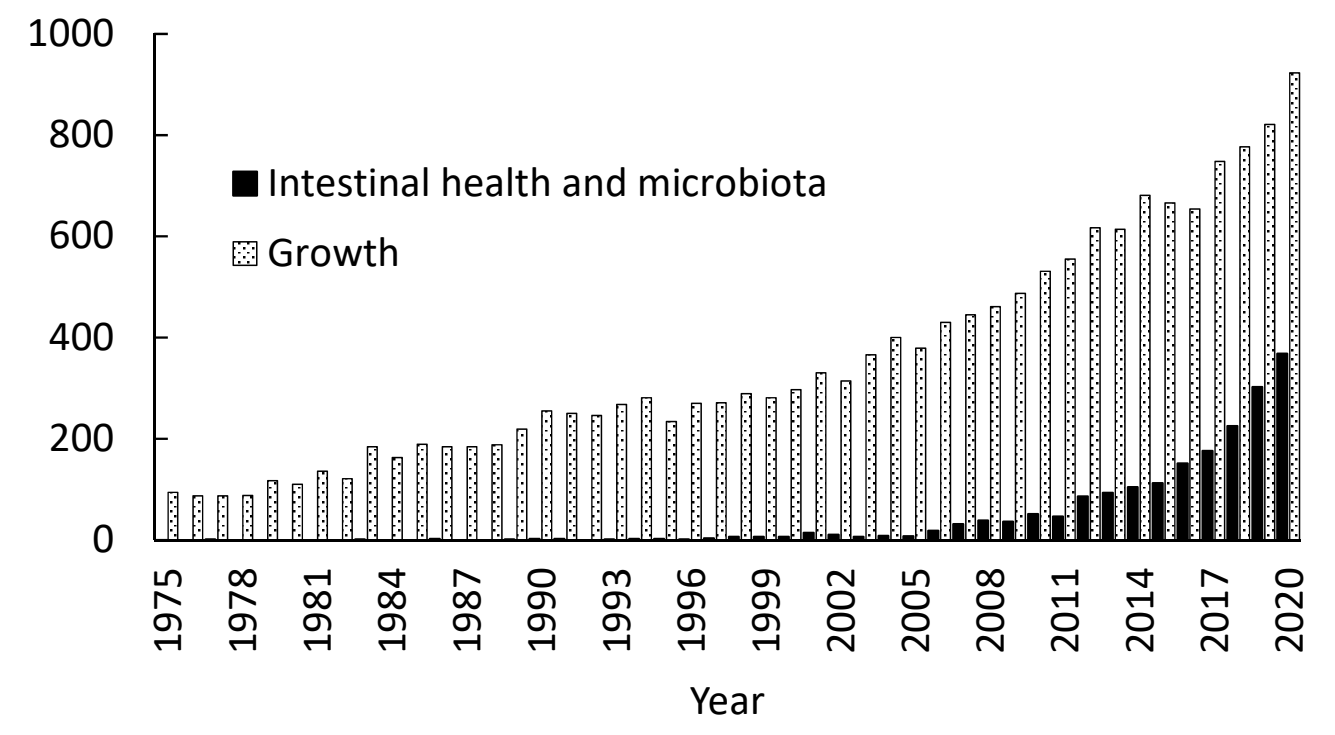

Figure 1. Number of peer-reviewed papers found in the PubMed. $\mathbf{\square}$ : using intestinal health and intestinal microbiota in pigs as keywords; $\mathbb{Z}_{\text {: using }}$ growth of pigs as keywords.

during the last 10 years (Figure 1). Even after consideration of a general increase of research activities in swine nutrition and production, based on the number of peer-reviewed papers shown in the PubMed, research on intestinal health and microbiota is near $40 \%$ of general growth performance research in 2020 , whereas it took less than $5 \%$ prior to 2007 or only less than $1 \%$ prior to 1997.

\section{INTESTINAL HEALTH}

The gastrointestinal tract is the largest and longest internal organ of pigs [15]. The intestine is separated into the small and large intestine. The small intestine is further divided to the duodenum, jejunum, and ileum. In pigs, the jejunum takes almost $80 \%$ of the small intestine (Figure 2 ) and where feeds are mostly digested to nutrients and then absorbed [13].

In the modern pig production, nursing piglets are weaned mostly at 3 to 4 weeks of age when they are too young considering that natural weaning occurs at around 8 to 10 weeks of age [16]. The intestine of early weaned pigs is premature with mucosal dysfunction $[17,18]$. This is the critical age for newly weaned pigs greatly affected by dietary factor. Conventional feeds given to newly weaned pigs include grains, legume seed meals, and animal byproducts. These feeds are

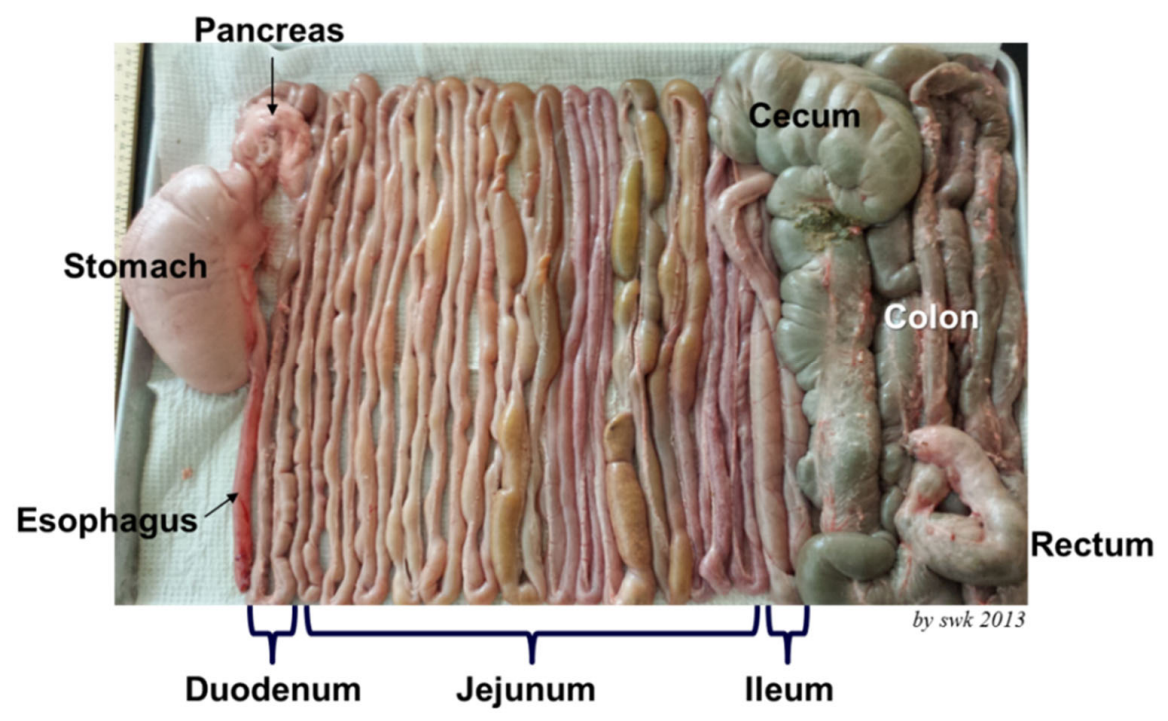

Figure 2. A photo of gastrointestinal tract of a pig at 5 weeks of age. The photo is taken by Sung Woo Kim in 2013 and also used in Eisemann and Kim [15]. 
essential sources of nutrients but also provide a notable amount of allergenic, antigenic, toxic, and pathogenic compounds to the intestine of newly weaned pigs [19-21]. Such stressors from the feeds often cause immune responses at the mucosal barrier of the jejunum followed by inflammatory responses and oxidative stress responses [22-26]. The jejunum is the major site of facing these challenges $[15,18$, $20,26]$ as well as for the feed digestion and nutrient absorption. Excessive inflammation and oxidative stress in the jejunum would cause destruction of villi and leaky gut resulting in reduced growth $[24,27,28]$.

\section{EVALUATION OF INTESTINAL HEALTH}

For the successful nutritional management of newly weaned pigs, therefore, prevention of unnecessary elevation of inflammation and oxidative stress in the jejunum would be the right direction. There can be several biological indicators to determine inflammatory status and oxidative stress status in the jejunum of pigs. Cytokines are small proteins secreted from cells for the communication among cells. Some cytokines (including tumor necrosis factor- $\alpha$ [TNF- $\alpha$ ], interleukin- $1 \beta$ [IL-1 $\beta$ ], IL-6, IL-8, and interferon- $\gamma$ ) functions as immunoregulatory molecules to activate immune cells causing inflammation and thus they are called pro-inflammatory cytokines [29], whereas cytokines (including IL-4, IL-10, and IL-13) reducing inflammatory responses are called anti-inflammatory cytokines [30]. Pro-inflammatory cytokines can be released from intestinal immune cells as well as mucosal epithelial cells $[31,32]$ by increased production of free radicals causing oxidative stress [33]. Excessive free radicals can damage cellular components including cell membranes and intracellular enzymes. Malondialdehydes and carbonyls are products of oxidative damages of lipids and protein, respectively, which are well accepted biological markers for oxidative stress [34-36].

Increased intestinal inflammation and oxidative stress cause damages in the intestinal epithelium and the structure of villi [37-39]. Crypt cell proliferation follows to repair damages in the intestinal epithelium [40,41]. Crypt cell proliferation can be quantified using immunohistochemistry by staining Ki67 proteins in proliferating cells [27,42,43]. Collective outcomes of intestinal inflammation, oxidative stress, epithelial damages, and crypt cell proliferation affect nutrient digestibility and eventually growth of pigs $[25,44,45]$.

A collective review of over 10 recent publications from our laboratory indicates that typical lean type nursery pigs with normal growth maintain 0.2 to $2.0 \mathrm{pg}$ TNF- $\alpha$ and 0.2 to $0.8 \mu \mathrm{mol}$ malondialdehydes per mg protein in the jejunal mucosa as selected examples. Increases of TNF- $\alpha$ and malondialdehydes showed negative correlation with growth of nursery pigs (Unpublished data). Nursery pigs with TNF- $\alpha$ greater than $0.6 \mathrm{pg}$ and malondialdehydes greater than 0.5 $\mu \mathrm{mol}$ per mg protein in the jejunal mucosa showed reduced weight gain. This example shows that selected inflammatory and oxidative stress measurements of the jejunal mucosa could be effective biomarkers for the intestinal health and thus potential growth of nursery pigs. Then nutritional strategies to maintain or improve intestinal health of pigs upon weaning could target altering some of these biomarkers. Recent publications, evaluating the effectiveness of these nutritional strategies, extensively target to affect the status in the jejunum by reducing the excessive release of pro-inflammatory cytokines and oxidative stress products. This alternation would maintain healthy villus structure with effective barrier functions which will in turn influence potential growth of nursery pigs.

\section{JEJUNAL MUCOSA-ASSOCIATED MICROBIOTA}

There has been an extended attention to understand the role of microbiota associated with the jejunal mucosa to maintain or improve the intestinal health of nursery pigs. The profile, so called relative abundance, of microbiota associated with intestinal mucosa is largely different from luminal microbiota associated with digesta in nursery pigs $[46,47]$. Their role or function to the host animal would be different. Luminal microbiota interacting with the digesta would affect nutrient digestion and secrete metabolites, whereas those associated to the intestinal mucosa are shown to crosstalk directly with intestinal immune cells [48-50] and prevent colonization of pathogenic bacteria [51]. There are increased efforts to provide research data characterizing jejunal mucosa-associated microbiota and dietary influences in pigs $[27,52,53]$. However, there is no clear understanding on the relationship between jejunal mucosa-associated microbiota and intestinal health in pigs and, therefore, statistical investigation of such relationships with recent data would provide critical tools to provide solutions for intestinal health of nursery pigs.

\section{NUTRITIONAL STRATEGIES TARGETING INTESTINAL HEALTH}

Animal nutritionists have evaluated and tested numerous alternative bioactive compounds, extracts, microorganisms, and feed additives to replace the use of AGP. The major target of these alternatives has been affecting and improving intestinal health of pigs with some promising outcomes but still without complete answers to replace AGP $[9,54,55]$. Potential and partial success has been obtained from the use of prebiotics [56,57], probiotics or direct-fed microbials [53,58], postbiotics [59-61], phytobiotics [62-64], non- 
starch polysaccharide degrading enzymes (NSPases) [24, 65-67], functional amino acids [68-70], acidifiers or organic acids [71,72], and other bioactive compounds [38,73,74].

Prebiotics traditionally used in feeds include fructo-oligosaccharides and manno-oligosaccharides, but also extend to xylo-oligosaccharides and milk oligosaccharides [57,75]. Recent research uses NSPases such as xylanase and mannanse as feed supplements in feeds to provide xylo-oligosaccharides and manno-oligosaccharides as sources of prebiotics in the intestine of pigs [25]. Probiotics has long been used in animal production. Effective probiotics are extensively lactogenic bacteria as they can reduce $\mathrm{pH}$ of the intestinal lumen and can potentially colonize or associate to the intestinal mucosa, together providing undesirable environment to pathogenic bacteria in the intestine. Recent research indicates that effective probiotic bacteria should associate to jejunal mucosa affecting immune cells in the small intestine [25,76]. Typical probiotics used in pig production include, but not limited to, Bacillus licheniformis, Bacillus subtilis, Bifidobacterium thermophilum, Bifidobacterium bifidum, Lactobacillus acidophilus, Lactobacillus plantarum, Lactobacillus reuteri, Saccharomyces cerevisiae, and Enterococcus fascium. Each strain of probiotics has a preferred environment based on availability of oxygen in the intestine of pigs. Effectiveness of probiotics with multiple strains should be compared with probiotics with a single strain. Postbiotics include bioactive compounds produced by probiotics during a fermentation process. This is a relatively new term but yeast culture $[59,60]$ and yeast cell wall extracts $[27,61]$ are examples of traditional postbiotics used in pig production.

Phytobiotics includes herbal extracts and essential oils that typically possess antioxidant, antibacterial, and antiviral properties [62-64,77]. Bioactive compounds in phytobiotics typically phenolic compounds with unique aroma [62]. Determination of an effective dose level would be an important item for the use of phytobiotics to prevent any potential negative impacts on feed intake. Feed enzymes degrading non-starch polysaccharides have been used in pig production mainly to provide additional nutrients by lessening cage effects of polysaccharides which entrap nutrients and feed particles in the small intestine of pigs [65-67]. However, recent research shows additional benefits of NSPases by converting NSP to potential prebiotics in the small intestine of pigs [24,25]. Some selected supplemental amino acids, such as arginine, glutamine, methionine, possess unique functions in the animal body. Methionine reduces oxidative stress in the intestinal epithelium [68], whereas glutamine prevents jejunal atrophy [78]. Arginine is also shown to be effective by its role in angiogenesis and vasodilation in the small intestine $[79,80]$.

A combinational use of multiple alternatives providing potential synergic benefits, so called synbiotics, is leading a recent trend of pig nutrition research [25,81-83].

\section{CONCLUSION}

Nursery pigs receive continuous challenges to the small intestine from dietary and environmental factors. Inflammation and oxidative stresses are initial factors impairing intestinal health and compromise potential growth of nursery pigs. Intestinal health status can be determined by quantification of selected inflammatory cytokines, oxidative stress products, and crypt cell proliferation in the jejunum. The profile of jejunal mucosa-associated microbiota are additional indicators of intestinal health warranting further research. Selected prebiotics, probiotics, postbiotics, and other bioactive compounds can be used in feeds to handle issues with intestinal health. Selection of these feed additives should aim modulating biomarkers indicating intestinal health and balancing intestinal microbiota.

\section{CONFLICT OF INTEREST}

We certify that there is no conflict of interest with any financial organization regarding the material discussed in the manuscript.

\section{ACKNOWLEDGMENTS}

The work was supported by North Carolina State University and North Carolina Agricultural Foundation.

\section{REFERENCES}

1. Farr MM, Wehr EE. Sulfamerazine therapy in experimental cecal coccidiosis of chickens. J Parasitol 1945;31:353-8. https:// doi.org/10.2307/3273032

2. Moore PR, Evenson A, Luckey TD, Mccoy E, Elvehjem CA, Hart EB. Use of sulfasuxidine, streptothricin, and streptomycin in nutritional studies with the chick. J Biol Chem 1946;165: 437-41. https://doi.org/10.1016/S0021-9258(17)41154-9

3. Whitehill AR, Oleson JJ, Hutchings BL. Stimulatory effect of aureomycin on the growth of chicks. Exp Biol Med 1950; 74:11-3. https://doi.org/10.3181/00379727-74-17793

4. Carpenter LE. The effect of antibiotics and vitamin $B_{12}$ on the growth of swine. Arch Biochem Biophys 1951;32:18791. https://doi.org/10.1016/0003-9861(51)90252-4

5. Cunha TJ, Meadows GB, Edwards HM, Sewell RF, Pearson AM, Glasscock RS. A comparison of aureomycin, streptomycin, penicillin and an aureomycin- $B_{12}$ feed supplement for the pig. Arch Biochem 1951;30:269-71.

6. Luecke RW, Thorp F, Newland HW, Mcmillen WN. The growth promoting effects of various antibiotics on pigs. J Anim Sci 1951;10:538-42. https://doi.org/10.2527/jas1951. $102538 \mathrm{x}$

7. Becker DE, Terrill SW, Notzold RA. Supplementary protein 
and the response of the pig to antibiotics. J Anim Sci 1955; 14:492-8. https://doi.org/10.2527/jas1955.142492x

8. Cromwell GL. Why and how antibiotics are used in swine production. Anim Biotechnol 2002;13:7-27. https://doi.org/ 10.1081/ABIO-120005767

9. Kim SW, Fan MZ, Applegate TJ. Nonruminant nutrition symposium on natural phytobiotics for health of young animals and poultry: mechanisms and application. J Anim Sci 2008;86(Suppl 14):E138-9. https://doi.org/10.2527/jas. 2007-0769

10. Casewell M, Friis C, Marco E, McMullin P, Phillips I. The European ban on growth-promoting antibiotics and emerging consequences for human and animal health. J Antimicrob Chemother 2003;52:159-61. https://doi.org/10.1093/jac/dkg 313

11. Sneeringer S, Bowman M, Clancy M. The U.S. and EU animal pharmaceutical industries in the age of antibiotic resistance. Washington, DC, USA: USDA; 2019. Report No.:ERR264.

12.Schoenmakers K. How China is getting its farmers to kick their antibiotics habit. Nature 2020;586:S60-2. https://doi. org/10.1038/d41586-020-02889-y

13. Pluske JR. Feed- and feed additives-related aspects of gut health and development in weanling pigs. J Anim Sci Biotechnol 2013;4:1. https://doi.org/10.1186/2049-1891-4-1

14. Gilliam R. Transitioning to antibiotic-free pig production: change your expectations [Internet]. National Hog Farmer; c2016 [cited 2016 Aug 19]. Available from: www.national hogfarmer.com/animal-well-being/transitioning-antibioticfree-pig-production-change-your-expectations

15.Eisemann J, Kim SW. Animal nutrition. Dubuque, IA, USA: Kendall Hunt Publishing; 2014.

16. Pond WG, Mersmann HJ. Biology of the domestic pig. Ithaca, NY, USA: Comstock Pub. Associates/Cornell University Press; 2001.

17.Smith F, Clark JE, Overman BL, et al. Early weaning stress impairs development of mucosal barrier function in the porcine intestine. Am J Physiol Gastrointest Liver Physiol 2010;298:G352-63. https://doi.org/10.1152/ajpgi.00081.2009

18. Moeser AJ, Ryan KA, Nighot PK, Blikslager AT. Gastrointestinal dysfunction induced by early weaning is attenuated by delayed weaning and mast cell blockade in pigs. Am J Physiol Gastrointest Liver Physiol 2007;293:G413-21. https:/doi.org/ 10.1152/ajpgi.00304.2006

19. Taliercio E, Kim SW. Epitopes from two soybean glycinin subunits are antigenic in pigs. J Sci Food Agric 2013;93:292732. https://doi.org/10.1002/jsfa.6113

20. Chaytor AC, Hansen JA, van Heugten E, See MT, Kim SW. Occurrence and decontamination of mycotoxins in swine feed. Asian-Australas J Anim Sci 2011;24:723-38. https:// doi.org/10.5713/ajas.2011.10358

21.Liener IE. Non-nutritive factors and bioactive compounds in soy. In: Drackley JK, editor. Soy in animal nutrition. Savoy,
IL, USA: Federation of Animal Science Societies; 2000. pp. 13-45.

22. Taliercio E, Kim SW. Identification of a second major antigenic epitope in the $\alpha$-subunit of soy $\beta$-conglycinin. Food Agric Immunol 2014;25:311-21. https://doi.org/10.1080/09540105. 2013.791969

23. Smith BN, Dilger RN. Immunomodulatory potential of dietary soybean-derived isoflavones and saponins in pigs. J Anim Sci 2018;96:1288-304. https://doi.org/10.1093/jas/sky036

24. Chen H, Zhang S, Kim SW. Effects of supplemental xylanase on health of the small intestine in nursery pigs fed diets with corn distillers' dried grains with solubles. J Anim Sci 2020;98: skaa185. https://doi.org/10.1093/jas/skaa185

25. Duarte ME, Tyus J, Kim SW. Synbiotic effects of enzyme and probiotics on intestinal health and growth of newly weaned pigs challenged with enterotoxigenic $\mathrm{F} 18^{+}$Escherichia coli. Front Vet Sci 2020;7:573. https://doi.org/10.3389/fvets.2020. 00573

26. Holanda DM, Kim SW. Efficacy of mycotoxin detoxifiers on health and growth of newly-weaned pigs under chronic dietary challenge of deoxynivalenol. Toxins 2020;12:311. https://doi. org/ 10.3390/toxins 12050311

27. Kim SW, Holanda DM, Gao X, Park I, Yiannikouris A. Efficacy of a yeast cell wall extract to mitigate the effect of naturally co-occurring mycotoxins contaminating feed ingredients fed to young pigs: impact on gut health, microbiome, and growth. Toxins 2019;11:633. https://doi.org/10.3390/toxins 11110633

28. Pearce SC, Mani V, Weber TE, et al. Heat stress and reduced plane of nutrition decreases intestinal integrity and function in pigs. J Anim Sci 2013;91:5183-93. https://doi.org/10.2527/ jas.2013-6759

29. Dinarello CA. Proinflammatory cytokines. Chest 2000;118: 503-8. https://doi.org/10.1378/chest.118.2.503

30. Opal SM, DePalo VA. Anti-inflammatory cytokines. Chest 2000;117:1162-72. https://doi.org/10.1378/chest.117.4.1162

31. Friedrich M, Pohin M, Powrie F. Cytokine networks in the pathophysiology of inflammatory bowel disease. Immunity 2019;50:992-1006. https://doi.org/10.1016/j.immuni.2019. 03.017

32.Xue X, Falcon DM. The role of immune cells and cytokines in intestinal wound healing. Int J Mol Sci 2019;20:6097. https:// doi.org/10.3390/ijms20236097

33. Bhattacharyya A, Chattopadhyay R, Mitra S, Crowe SE. Oxidative stress: an essential factor in the pathogenesis of gastrointestinal mucosal diseases. Physiol Rev 2014;94:329-54. https://doi.org/10.1152/physrev.00040.2012

34. Berchieri-Ronchi CB, Kim SW, Zhao Y, Correa CR, Yeum KJ, Ferreira ALA. Oxidative stress status of highly prolific sows during gestation and lactation. Animal 2011;5:1774-9. https://doi.org/10.1017/S1751731111000772

35.Zhao Y, Flowers WL, Saraiva A, Yeum KJ, Kim SW. Effect of 
social ranks and gestation housing systems on oxidative stress status, reproductive performance, and immune status of sows. J Anim Sci 2013;91:5848-58. https://doi.org/10.2527/jas.20136388

36.Zhao Y, Kim SW. Oxidative stress status and reproductive performance of sows during gestation and lactation under different thermal environments. Asian-Australas J Anim Sci 2020;33:722-31. https://doi.org/10.5713/ajas.19.0334

37.Lee IK, Kye YC, Kim G, et al. Stress, nutrition, and intestinal immune responses in pigs - a review. Asian-Australas J Anim Sci 2016;29:1075-82. https://doi.org/10.5713/ajas.16.0118

38. Jang KB, Kim SW. Supplemental effects of dietary nucleotides on intestinal health and growth performance of newly weaned pigs. J Anim Sci 2019;97:4875-82. https://doi.org/10.1093/ jas/skz334

39. Patankar JV, Becker C. Cell death in the gut epithelium and implications for chronic inflammation. Nat Rev Gastroenterol Hepatol 2020;17:543-56. https://doi.org/10.1038/s41575020-0326-4

40.Kuhn KA, Manieri NA, Liu TC, Stappenbeck TS. IL-6 stimulates intestinal epithelial proliferation and repair after injury. PLoS One 2014;9:e114195. https://doi.org/10.1371/journal. pone. 0114195

41. MacDonald TT. Epithelial proliferation in response to gastrointestinal inflammation. Ann NY Acad Sci 1992;664:202-9. https://doi.org/10.1111/j.1749-6632.1992.tb39761.x

42. Tiwari UP, Chen H, Kim SW, Jha R. Supplemental effect of xylanase and mannanase on nutrient digestibility and gut health of nursery pigs studied using both in vivo and in vitro models. Anim Feed Sci Technol 2018;245:77-90. https://doi. org/10.1016/j.anifeedsci.2018.07.002

43. Charepalli V, Reddivari L, Radhakrishnan S, et al. Pigs, unlike mice, have two distinct colonic stem cell populations similar to humans that respond to high-calorie diet prior to insulin resistance. Cancer Prev Res 2017;10:442-50. https://doi.org/ 10.1158/1940-6207.CAPR-17-0010

44. Chen H, Zhang S, Park I, Kim SW. Impacts of energy feeds and supplemental protease on growth performance, nutrient digestibility, and gut health of pigs from 18 to $45 \mathrm{~kg}$ body weight. Anim Nutr 2017;3:359-65. https://doi.org/10.1016/ j.aninu.2017.09.005

45. Guan G, Abul Kalam Azad M, Lin Y, et al. Biological effects and applications of chitosan and chito-oligosaccharides. Front Physiol 2019;10:516. https://doi.org/10.3389/fphys.2019. 00516

46. Burrough ER, Arruda BL, Plummer PJ. Comparison of the luminal and mucosa-associated microbiota in the colon of pigs with and without swine dysentery. Front Vet Sci 2017;4: 139. https://doi.org/10.3389/fvets.2017.00139

47. Adhikari B, Kim SW, Kwon YM. Characterization of microbiota associated with digesta and mucosa in different regions of gastrointestinal tract of nursery pigs. Int J Mol Sci 2019;
20:1630. https://doi.org/10.3390/ijms20071630

48. Belkaid Y, Hand TW. Role of the microbiota in immunity and inflammation. Cell 2014;157:121-41. https://doi.org/ 10.1016/j.cell.2014.03.011

49. Mulder IE, Schmidt B, Lewis M, et al. Restricting microbial exposure in early life negates the immune benefits associated with gut colonization in environments of high microbial diversity. PLoS One 2011;6:e28279. https://doi.org/10.1371/ journal.pone.0028279

50. Arpaia N, Campbell C, Fan X, et al. Metabolites produced by commensal bacteria promote peripheral regulatory T-cell generation. Nature 2013;504:451-5. https://doi.org/10.1038/ nature12726

51.Buffie CG, Pamer EG. Microbiota-mediated colonization resistance against intestinal pathogens. Nat Rev Immunol 2013;13:790-801. https://doi.org/10.1038/nri3535

52.Jang KB, Purvis JM, Kim SW. Supplemental effects of dietary lysophospholipids in lactation diets on sow performance, milk composition, gut health, and gut-associated microbiome of offspring. J Anim Sci 2020;98:skaa227. https://doi.org/10. 1093/jas/skaa227

53.Li P, Niu Q, Wei Q, et al. Microbial shifts in the porcine distal gut in response to diets supplemented with Enterococcus faecalis as alternatives to antibiotics. Sci Rep 2017;7:41395. https://doi.org/10.1038/srep41395

54. Thacker PA. Alternatives to antibiotics as growth promoters for use in swine production: a review. J Anim Sci Biotechnol 2013;4:35. https://doi.org/10.1186/2049-1891-4-35

55. Yin J, Conlon M, Kim SW. Nutrients and inflammatory diseases. Mediators Inflamm 2017;2017:6134909. https://doi.org/10. $1155 / 2017 / 6134909$

56. Flickinger EA, van Loo J, Fahey GC. Nutritional responses to the presence of inulin and oligofructose in the diets of domesticated animals: a review. Crit Rev Food Sci Nutr 2003; 43:19-60. https://doi.org/10.1080/10408690390826446

57.Jang KB, Purvis JM, Kim SW. Dose-response and functional role of whey permeate as a source of lactose and milk oligosaccharides on intestinal health and growth of nursery pigs. J Anim Sci 2021;99:skab008. https://doi.org/10.1093/jas/skab 008

58. Barba-Vidal E, Martín-Orúe SM, Castillejos L. Review: are we using probiotics correctly in post-weaning piglets? Animal 2018;12:2489-98. https://doi.org/10.1017/S17517311180 00873

59. Mathew AG, Chattin SE, Robbins CM, Golden DA. Effects of a direct-fed yeast culture on enteric microbial populations, fermentation acids, and performance of weanling pigs. J Anim Sci 1998;76:2138-45. https://doi.org/10.2527/1998.7682138x

60.Shen YB, Piao XS, Kim SW, et al. Effects of yeast culture supplementation on growth performance, intestinal health, and immune response of nursery pigs. J Anim Sci 2009;87:261424. https://doi.org/10.2527/jas.2008-1512 
61. Holanda DM, Yiannikouris A, Kim SW. Investigation of the efficacy of a postbiotic yeast cell wall-based blend on newlyweaned pigs under a dietary challenge of multiple mycotoxins with emphasis on deoxynivalenol. Toxins 2020;12:504. https:// doi.org/10.3390/toxins12080504

62. Kommera SK, Mateo RD, Neher FJ, Kim SW. Phytobiotics and organic acids as potential alternatives to the use of antibiotics in nursery pig diets. Asian-Australas J Anim Sci 2006; 19:1784-9. https://doi.org/10.5713/ajas.2006.1784

63. Kong X, Yin Y, Wu G, et al. Dietary supplementation with acanthopanax senticosus extract modulates cellular and humoral immunity in weaned piglets. Asian-Australas J Anim Sci 2007;20:1453-61. https://doi.org/10.5713/ajas. 2007.1453

64.Lu T, Piao XL, Zhang Q, Wang D, Piao XS, Kim SW. Protective effects of Forsythia suspensa extract against oxidative stress induced by diquat in rats. Food Chem Toxicol 2010;48: 764-70. https://doi.org/10.1016/j.fct.2009.12.018

65. Kim SW, Knabe DA, Hong KJ, Easter RA. Use of carbohydrases in corn-soybean meal-based nursery diets. J Anim Sci 2003; 81:2496-504. https://doi.org/10.2527/2003.81102496x

66. Passos AA, Park I, Ferket P, von Heimendahl E, Kim SW. Effect of dietary supplementation of xylanase on apparent ileal digestibility of nutrients, viscosity of digesta, and intestinal morphology of growing pigs fed corn and soybean meal based diet. Anim Nutr 2015;1:19-23. https://doi.org/10.1016/j.aninu. 2015.02.006

67. Duarte ME, Zhou FX, Dutra WM, Kim SW. Dietary supplementation of xylanase and protease on growth performance, digesta viscosity, nutrient digestibility, immune and oxidative stress status, and gut health of newly weaned pigs. Anim Nutr 2019;5:351-8. https://doi.org/10.1016/j.aninu.2019.04.005

68. Shen YB, Weaver AC, Kim SW. Effect of feed grade L-methionine on growth performance and gut health in nursery pigs compared with conventional DL-methionine. J Anim Sci 2014;92:5530-9. https://doi.org/10.2527/jas.2014-7830

69. Kim SW, Mateo RD, Yin YL, Wu G. Functional amino acids and fatty acids for enhancing production performance of sows and piglets. Asian-Australas J Anim Sci 2007;20:295306. https://doi.org/10.5713/ajas.2007.295

70.Kim SW, Chen H, Parnsen W. Regulatory role of amino acids in pigs fed on protein-restricted diets. Curr Protein Pept Sci 2019;20:132-8. https://doi.org/10.2174/13892037196661805 17100746

71. Pearlin BV, Muthuvel S, Govidasamy P, et al. Role of acidifiers in livestock nutrition and health: a review. J Anim Physiol Anim Nutr 2020;104:558-69. https://doi.org/10.1111/jpn. 13282

72. Ferronato G, Prandini A. Dietary supplementation of inorganic, organic, and fatty acids in pig: a review. Animals 2020;
10:1740. https://doi.org/10.3390/ani10101740

73. Weaver AC, Kim SW. Supplemental nucleotides high in inosine 5 '-monophosphate to improve the growth and health of nursery pigs. J Anim Sci 2014;92:645-51. https://doi.org/10. 2527/jas.2013-6564

74. Tan C, Ji Y, Zhao X, et al. Effects of dietary supplementation of nucleotides from late gestation to lactation on the performance and oxidative stress status of sows and their offspring. Anim Nutr 2020 Dec 28 [Epub]. https://doi.org/10.1016/j. aninu.2020.10.004

75. Tran THT, Everaert N, Bindelle J. Review on the effects of potential prebiotics on controlling intestinal enteropathogens Salmonella and Escherichia coli in pig production. J Anim Physiol Anim Nutr 2018;102:17-32. https://doi.org/10.1111/ jpn.12666

76.Sun Y, Duarte ME, Kim SW. Dietary inclusion of multispecies probiotics in preventing post-weaning diarrhea caused by F18 ${ }^{+}$E. coli in pigs. Anim Nutr 2021 Jan 14 [Accepted].

77.Sun Y, Kim SW. Intestinal challenge with enterotoxigenic Escherichia coli in pigs, and nutritional intervention to prevent postweaning diarrhea. Anim Nutr 2017;3:322-30. https:// doi.org/10.1016/j.aninu.2017.10.001

78. Wu G, Meier SA, Knabe DA. Dietary glutamine supplementation prevents jejunal atrophy in weaned pigs. J Nutr 1996; 126:2578-84. https://doi.org/10.1093/jn/126.10.2578

79. Kim SW, McPherson RL, Wu G. Dietary arginine supplementation enhances the growth of milk-fed young pigs. J Nutr 2004;134:625-30. https://doi.org/10.1093/jn/134.3.625

80.Zhan Z, Ou D, Piao X, Kim SW, Liu Y, Wang J. Dietary arginine supplementation affects microvascular development in the small intestine of early-weaned pigs. J Nutr 2008;138:13049. https://doi.org/10.1093/jn/138.7.1304

81. Brousseau JP, Talbot G, Beaudoin F, Lauzon K, Roy D, Lessard M. Effects of probiotics Pediococcus acidilactici strain MA18/5M and Saccharomyces cerevisiae subsp. boulardii strain SBCNCM I-1079 on fecal and intestinal microbiota of nursing and weanling piglets. J Anim Sci 2015;93:5313-26. https:// doi.org/10.2527/jas.2015-9190

82. McConn BR, Duttlinger AW, Kpodo KR, Eicher SD, Richert BT, Johnson JS. Replacing dietary antibiotics with $0.20 \%$ ${ }_{\mathrm{L}}$-glutamine and synbiotics following weaning and transport in pigs. J Anim Sci 2020;98:skaa272. https://doi.org/10.1093/ jas/skaa272

83. Rodríguez-Sorrento A, Castillejos L, López-Colom P, et al. Effects of Bifidobacterium longum subsp. infantis CECT 7210 and Lactobacillus rhamnosus HN001, combined or not with oligofructose-enriched inulin, on weaned pigs orally challenged with Salmonella typhimurium. Front Microbiol 2020;11:2012. https://doi.org/10.3389/fmicb.2020.02012 